\title{
Comparison between optical readable and open-ended weighed food records
}

\author{
Margaretha Nydahl'*, Inga-Britt Gustafsson², Rawya Mohsen ${ }^{3}$ \\ and Wulf Becker ${ }^{4,5}$
}

'Department of Food, Nutrition and Dietetics, Uppsala University, BMC, Uppsala, Sweden; ${ }^{2}$ Department of Restaurant and Culinary Art, Örebro University, Sweden; ${ }^{3}$ Department of Public Health and Caring Sciences/Geriatrics, Uppsala University, Sweden; ${ }^{4}$ National Food Administration, Uppsala, Sweden; ${ }^{5}$ Department of Public Health and Caring

Sciences, Clinical Nutrition and Metabolism, Uppsala University, Sweden

\section{Abstract}

Background: A simplified optically readable food record (ORFR) was developed and compared with an openended weighed record (WR).

Objective: To compare intake of nutrients and foods using a seven-day ORFR with intake estimated using a seven-day WR. The results from each method were validated against 24-h urine nitrogen excretion and energy intake (EI)/estimated basal metabolic rate (BMR) cut-off values.

Design: The study comprised 73 free-living, healthy 70-year-old Swedish men. Dietary data were collected during seven consecutive days, starting either with WR or ORFR.

Results: Average intakes of energy and several nutrients were significantly lower when estimated using ORFR than when using WR. However, when adjusted for nutrient density, only a few nutrients were still lower with ORFR. Spearman correlation coefficients between the two methods regarding intakes of energy and energyyielding nutrients were moderate to high, i.e. 0.4-0.6, while figures for most micro-nutrients were in the range 0.3-0.5. A large proportion of subjects under-reported their EIs, a higher proportion doing so when using ORFR. Protein intake obtained using ORFR was 31\% lower than the values calculated from the 24-h urine nitrogen excretion, and 22\% lower than those obtained from WR. Average intakes of milk, cheese and other milk products as well as coffee, tea and alcohol were significantly higher when estimated using ORFR than when using WR, while intakes of vegetables, meat and meat products, fish, bread and cereal products as well as number of sweet foods were significantly lower with ORFR.

Conclusions: Based on these results, adjustments of some portion sizes in ORFR are suggested. In view of the advantages of ORFR with respect to lower response burden and rapid processing of data, such adjustments would make ORFR a suitable dietary assessment tool for use in dietary surveys, including larger resourcedemanding epidemiological investigations.

Keywords: optically readable food record; weighed registration; urine nitrogen; portion sizes

Received: 20 October 2008; Revised: 19 December 2008; Accepted: 20 January 2009; Published: 20 February 2009

A ccurate estimates of the dietary intake of freeliving individuals are required for nutritional research, epidemiology and clinical medicine. However, all dietary assessment methods in which people report their habitual food intake rely on the information supplied by the subjects. Unfortunately, although methodology and procedures, i.e. computer techniques, have improved in recent years, there is great consensus that no dietary assessment method has been proven to accurately reflect an individual's long-term dietary intake. A large number of trials have shown an apparent underestimation of energy intakes (EIs), not only in overweight subjects, but also in other groups (1-6). This problem has also been discussed in a review by Goldberg and Black (7) and in a study by Willett et al. (8), where the authors suggested routines that should be included in dietary assessment methods to increase the accuracy of EI evaluations.

In the early 1980 s, it was suggested that $24-\mathrm{h}$ urine nitrogen (UN) output could be used as a validity test in dietary surveys (9). This is an indirect check of protein intake, but has the advantage of being reliable. Furthermore, the 24-h UN method is inexpensive compared with other biological markers used. Studies using 24-h UN 
excretion have shown that protein intakes estimated with various methods recalling food intake tended to be too low indicating under-reporting (9-13).

Two widely used methods of assessing the dietary intake of free-living persons are the menu book (including recently simplified food records) and open weighed food records. Both methods have been used in large population groups. They are considered rather expensive methods, primarily because they are time-consuming for the investigator $(5,14-16)$. Therefore, a pre-coded sevenday record book was developed and has been used in several investigations of different population groups in Sweden $(5,15,16)$. The record book was compared with an open weighed record (WR) method, and it was found to be very easy to use, but needed further development and improvements (15).

To reduce the time spent on data entry and coding, an optically readable version of the record book was developed. The optically readable food record (ORFR) has the same content of food items/dishes, but data can be entered into the computer automatically by optical reading of each page. This procedure has the advantage of minimising errors that occur at data entry.

Main objective of the present investigation was to evaluate the ORFR for use in a healthy free-living elderly male population. An open WR was used as the reference method. Estimates of the intake of foods as well as energy and some of the main nutrients were compared when using the two methods. In addition, protein intake was validated against $24-\mathrm{h}$ UN excretion in the elderly male population.

\section{Methods}

\section{Subjects}

Dietary data were collected from 73 male subjects, all 70 years of age. The subjects were enrolled in a health survey, which started in 1970-1973 (17). All 50-year-old men living in the Municipality of Uppsala at the time were invited to participate in a health survey on risk factors for coronary heart disease. About 2,000 men have been investigated every tenth year since then. About 20 years later, a follow-up investigation of the 70-year-old 'survivors' was conducted. A total of 855 men have been investigated and a subgroup $(n=75)$ was randomly selected and asked to take part in the present study. The men visited the metabolic clinic at the University Hospital as part of the ongoing health survey. Those who agreed to report their dietary intake during two separate weeks were included in the present study.

\section{Outline of the study}

The subjects were recruited throughout November and May and were randomly assigned to start either with the ORFR or with the WR. Each subject was weighed initially and at the end of each dietary recording period including seven consecutive days, with a break of one week between the two periods. Each subject received detailed oral and written instructions from a dietician or nurse on how to record food intake using the WR or the ORFR, as well as instructions on how to use the scales. Information on how to fill in the records correctly was also given in a video film that was shown to each participant. Subjects were instructed to continue their normal eating habits, and to start filling in the dietary record the following day. If further questions arose during the week of reporting, subjects were instructed to contact the dietician or nurse by phone for assistance.

Each subject recorded his intake in the ORFR by marking a horizontal pencil stroke in a 'circel'. Each page of the ORFR contains pre-printed food items or dishes eaten at main meals, and the subject has to mark the amount of food eaten, expressed either in household measurements or as portion sizes. Subjects also indicated where and when foods were consumed. The portion sizes were illustrated in a series of four photographs, as a guide to estimating the portions of the meal components (meat/ fish; potatoes/pasta/rice; vegetables/salad, etc.). Use of spreads on sandwiches was also estimated with the help of photographs showing four alternatives for the amounts used. For the other pre-printed foods, the subject indicated the amount consumed in household measures, e.g. glasses, cups, slices, etc. Predefined standard portions were allocated in the data analyses. These portions were mainly derived from Swedish reference publications (Food Weight Tables. National Food Administration, Uppsala, Sweden, In Swedish). Food items under the heading 'others' were described by the subjects in free text and were coded into the computer by hand in accordance with the National Food Administration's food composition database (18).

Each page was read by an optical reader (Kaiser OMR 32) using the OMR technique, where the position of the marking on the page constitutes the necessary information. The optical reader is equipped with an extrasensitive head for reading, which sends out visible light at a reading speed of 3,000 pages/h. The reader is linked to a PC. The Kaiser LEPRON program transfers the data to the PC, where it is accessed and analysed.

The subjects were instructed to weigh all the foods eaten during the seven-day period using a scale (Soehnle, model 8020). As the subjects were retired men, the majority of their meals were eaten at home, according to a regular eating pattern. If for any reason they were to eat away from home, they were asked to bring the scale with them. In some situations where they were unable to weigh their food, they would estimate their food intake using the same set of photographs as for the ORFR. The subjects were instructed to record their intake of food and beverages in a small notebook specially prepared for the 
present study. Further, they were instructed to record any intake as soon as possible after consumption of any food or drink.

All subjects were asked to collect a 24-h urine sample during the weighed food record period. Protein intake was validated by comparing the estimated intake from the food records with the protein intake calculated from the 24-h UN excretion (9). Oral and written instructions on the collection technique were given to each subject. The subjects were given a plastic litre measure for collecting the urine, and two-litre plastic bottles for storing the urine collections. Each bottle contained $5 \mathrm{~g}$ boric acid as preservative. The first morning urine voided on the collection day was discarded and the time noted. All urine passed in the next $24 \mathrm{~h}$ was collected until the same time the next morning. To check the completeness of urine collection, para-amino-benzoic acid (PABA) tables were used $(10,11)$. The subjects were instructed to take the PABA tablets $(380 \mathrm{mg}$ ) during the 24-h urine collection. One tablet was taken with each of the three main meals, i.e. breakfast, lunch and dinner. To include all days of the week, the urine collections were spread out over the week. Individual urine specimens for each 24-h period were carefully mixed. Aliquots of the 24-h collections were stored at $-20^{\circ} \mathrm{C}$ prior to analysis. The urine collections containing less than $85 \%$ were considered incomplete. UN excretion was converted to grams of protein ingested using the formula gram $\mathrm{N} / 0.81 \times 6.25$, as suggested by Bingham and Cummings (10), as it was found that, on average, $81 \%$ of the nitrogen is excreted with the urine.

\section{Calculation of energy and nutrient intakes}

The daily intakes of energy and selected nutrients were calculated using a computerised dietary assessment program (19) equipped with a food composition database from the National Food Administration (20). The database includes about 1,500 food items, drinks and standard recipes, and reports data on energy and 47 nutrients. The adequacy of the recorded EI values was evaluated using the cut-off method, according to Goldberg et al. (23). This is based on reported EI divided by estimated BMR (23). A cut-off value below 1.27 for EI/estimated BMR was used to identify subjects with apparent long-term under-reporting. This value is considered as the lower limit for long-term survival (21). In addition, a cut-off value of 1.1 was used to characterise subjects with an 'implausibly low' EI for a seven-day period based on statistical considerations described by Goldberg et al. (23).

\section{Statistical analysis}

The Statistical Analysis System (24) for Personal Computers Release 6.04 was used for the statistical analyses.
The results are expressed as means \pm standard deviation. For comparison of means of normally distributed variables, the paired Student's t-test was used. For variables not normally distributed, the Wilcoxon rank sum test was applied. Correlation analysis was performed with Spearman's rank correlation to test for the trend in the different quintiles of the main variables (25). Pearson correlation was used to test the linear relationship among some of the variables.

\section{Results}

\section{Subjects}

Seventy-three of the 75 men completed both recordings: one week using the optical readable food record and one week using the weighed food registration method. Two subjects failed to complete the recordings adequately. There were no significant differences in body weight from baseline, ORFR $82.7 \pm 11.4 \mathrm{~kg}$ and WR $82.5 \pm 11.4 \mathrm{~kg}$, to the end of either of the two dietary recording periods, ORFR $82.7 \pm 11.5 \mathrm{~kg}$ and WR $82.7 \pm 11.2 \mathrm{~kg}$, or between the two methods used.

\section{Intakes of energy and nutrients}

The mean daily intakes of energy and selected nutrients as measured with the two methods are shown in Table 1. Average daily intakes of energy and several nutrients differed significantly between the two methods. Higher average intakes were obtained by the WR for energy and protein, total fat, carbohydrates, B-carotene, vitamin $\mathrm{D}$, $\alpha$-tocopherol, thiamin, riboflavin, preformed niacin, vitamin $\mathrm{B}_{6}$, folate, vitamin $\mathrm{C}$, magnesium, iron, zinc, selenium and dietary fibre. However, the proportion of energy $(\mathrm{E} \%)$ from energy-yielding nutrients was similar, except for a higher $\mathrm{E} \%$ saturated fatty acids and alcohol, and a lower $\mathrm{E} \%$ sucrose, with the ORFR method.

When expressed as nutrient density (i.e. amount per MJ), the ORFR yielded lower nutrient density for iron, calcium, $\beta$-carotene, selenium, $\alpha$ - tocopherol and dietary fibre, while a higher nutrient density was found for potassium (Table 2). Lower intakes per MJ were also obtained with the ORFR for the fatty acids 16:1, 18:1 and 18:3 $n-3$ and the long-chain $n$-3 fatty acids 20:5 and 22:6 (data not shown).

The correlation coefficients (Spearman) between the two dietary assessment methods for intakes of energy and nutrients ranged from 0.08 to 0.68 and were all significant $(p<0.01)$. Moderate to high correlation coefficients, $>0.40-0.60$, were obtained for energy and most energyyielding nutrients (Table 3), while coefficients were between 0.30 and 0.50 for most micro-nutrients (Table 4). Lower figures $(<0.30)$ were obtained for vitamin $\mathrm{A}$, vitamin $\mathrm{D}, \mathrm{B}$-carotene, thiamin, riboflavin, preformed niacin and sodium. A comparison of the 
Table 1. Average daily intakes of energy, nutrients and alcohol as measured by the ORFR and the weighed record (WR); mean and (SD) $(n=73)$

\begin{tabular}{|c|c|c|c|c|}
\hline \multirow[b]{2}{*}{ Energy (kJ) } & \multicolumn{2}{|c|}{ ORFR } & \multicolumn{2}{|c|}{ WR } \\
\hline & $7,525 * * * *$ & $(2,222)$ & 8,332 & $(1,690)$ \\
\hline Protein (g) & $69 * * *$ & (19) & 77 & $(16)$ \\
\hline Protein (E\%) & 16 & (2) & 16 & (2) \\
\hline Total fat (g) & $72^{*}$ & (25) & 78 & (19) \\
\hline Total fat (E\%) & 35 & (5) & 34 & (5) \\
\hline Saturated fat (E\%) & $15^{* * * *}$ & (3) & 14 & (3) \\
\hline Monounsaturated fat (E\%) & 12 & (2) & 12 & (2) \\
\hline Polyunsaturated fat (E\%) & 5 & (I) & 5 & (I) \\
\hline Total carbohydrates (g) & $210 * * *$ & (67) & 235 & (57) \\
\hline Total carbohydrates (E\%) & 48 & (5) & 48 & (6) \\
\hline Alcohol (g) & 6.4 & $(6.3)$ & 6.0 & (6.9) \\
\hline Alcohol (E\%) & $3 * *$ & (3) & 2 & (2) \\
\hline Dietary fibre (g) & $17.5 * * *$ & $(5.7)$ & 20.4 & $(5.2)$ \\
\hline Vitamin A (RE) & 1.52 & $(0.87)$ & 1.50 & $(1.03)$ \\
\hline Retinol (mg) & 1.25 & $(0.86)$ & 1.06 & $(0.96)$ \\
\hline$\beta$-carotene (mg) & $1.61 * *$ & $(1.12)$ & 2.62 & $(2.22)$ \\
\hline Vitamin D $(\mu g)$ & $6.2^{* *}$ & $(2.5)$ & 7.1 & $(2.3)$ \\
\hline$\alpha$-tocopherol (mg) & $6.0 * * *$ & $(2.1)$ & 7.2 & $(1.8)$ \\
\hline Thiamin (mg) & $1.24 * * *$ & $(0.36)$ & 1.45 & $(0.38)$ \\
\hline Riboflavin (mg) & $1.54 * * *$ & $(0.46)$ & 1.66 & $(0.47)$ \\
\hline Niacin (pref.) (mg) & $14.1^{* *}$ & (3.7) & 15.8 & (3.8) \\
\hline Vitamin $B_{6}(\mathrm{mg})$ & $1.70^{*}$ & $(0.50)$ & 1.81 & $(0.40)$ \\
\hline Vitamin $B_{12}(\mu g)$ & 7.5 & $(6.1)$ & 7.7 & $(7.3)$ \\
\hline Folate $(\mu \mathrm{g})$ & $195^{* * * *}$ & (57) & 217 & (49) \\
\hline Vitamin C (mg) & $54^{*}$ & (29) & 63 & (34) \\
\hline Calcium (mg) & 966 & (344) & 926 & (249) \\
\hline Potassium (mg) & 2,784 & (744) & 2,960 & (569) \\
\hline Magnesium (mg) & $287^{*}$ & (74) & 305 & (55) \\
\hline Iron (mg) & $13.0 * * *$ & $(4.0)$ & 15.8 & (5.3) \\
\hline Zinc (mg) & $9.7^{*}$ & $(2.8)$ & 10.4 & $(2.3)$ \\
\hline Selenium $(\mu \mathrm{g})$ & $27^{* * * *}$ & (8) & 34 & (I3) \\
\hline
\end{tabular}

Values significantly different from weighed record: ${ }^{*} p<0.05$; ${ }^{* *} p<0.0$ I; $*^{* * *} p<0.001$.

ranking of the individual intakes of energy and selected nutrients showed that the majority were classified into the same quintile or nearest quintile, i.e. the one below or the one above (Table 4$)$.

\section{Urine nitrogen excretion}

All subjects $(n=73)$ collected a 24 -h urine sample during the weighed food record period. As we considered urine samples with a recovery of less than $85 \%$ incomplete, only 59 samples were used for comparison with the respective dietary records. The daily protein intake estimated using ORFR was $31 \%$ lower than the calculated values from the 24-h UN ( $p<0.0667, r=0.59)$, while that estimated using the WR was $22 \%$ lower $(p<0.0001, r=0.27)$ (Table 5).
Table 2. Nutrient density (per MJ) according to ORFR and WR $(n=73)$

\begin{tabular}{lccc}
\hline & ORFR & WR & $\begin{array}{c}\text { Mean difference } \\
\text { WR-ORFR }\end{array}$ \\
\hline$\beta$-carotene $(\mathrm{mg})$ & 0.22 & 0.32 & $-0.1 \mathrm{I}^{* * *}$ \\
$\alpha$-tocopherol $(\mathrm{mg})$ & 0.80 & 0.87 & $-0.06^{* * *}$ \\
Iron $(\mathrm{mg})$ & 1.74 & 1.88 & $-0.14^{* *}$ \\
Dietary fibre $(\mathrm{g})$ & 2.36 & 2.48 & $-0.12^{*}$ \\
Calcium $(\mathrm{mg})$ & 129 & 112 & $-16.5^{* * *}$ \\
Potassium $(\mathrm{mg})$ & 378 & $36 \mathrm{I}$ & $17.4^{*}$ \\
Selenium $(\mu \mathrm{g})$ & 3.63 & 4.16 & $-0.53^{* *}$ \\
\hline
\end{tabular}

Significant difference between ORFR and WR: ${ }^{*} p<0.05 ;{ }^{*} p<0.0$; **** $p<0.001$.

\section{Food consumption}

The average daily consumption of foods (aggregated into major food groups) obtained by the two methods is shown in Table 6. The consumption of cheese, milk and other milk products as well as coffee, tea and alcohol was significantly higher when estimated using the ORFR method than when using the WR method, while the opposite was seen for vegetables, meat and meat products, fish, bread, cereals and pasta, cakes and biscuits, jam, sweet drinks and desserts, chocolate and sugar (Table 6). No differences were seen for spreads, potatoes, fruit, juice and eggs.

\section{Cut-off limits for identifying under-reporting}

A large proportion of the men under-reported their EI. Use of the cut-off point $<1.27$ (21) showed a majority of the men reported an EI below this value when using the ORFR and WR, respectively. Further, it was found that a higher percentage had an implausibly low EI according to Goldberg, i.e. cut-off $<1.1$ (23), when using the ORFR $(26 \%)$ than when using the WR $(12 \%)$.

\section{Discussion}

The main results from the present study show that estimates of average intakes of energy and several nutrients differed significantly between the two methods, higher figures being obtained when using the WR. However, when expressed as nutrient density, i.e. per MJ, only a few nutrients were still lower when using the ORFR. The mean Spearman correlation coefficients between the intakes of energy and energy-yielding nutrients between the two methods were moderate to high, i.e. $0.4-0.6$, while figures for most micro-nutrients were in the range $0.3-0.5$. The majority of the subjects' intakes were classified into the same or adjacent quintile.

In a series of dietary surveys earlier performed in Sweden, a pre-coded record book has been used to 
Table 3. Cross-classification (quintiles) and correlation of intakes of energy, energy-yielding nutrients and dietary fibre (in absolute and energy-adjusted values), according to ORFR and WR

\begin{tabular}{|c|c|c|c|}
\hline & \multicolumn{2}{|c|}{$\begin{array}{c}\text { Cross- } \\
\text { classification, \% }\end{array}$} & \multirow{2}{*}{$\begin{array}{c}\begin{array}{c}\text { Spearman } \\
\text { correlation }^{c}\end{array} \\
r\end{array}$} \\
\hline & $\begin{array}{l}\text { WR QI } \\
\text { vs ORFR } \\
\text { QI+Q2 }\end{array}$ & $\begin{array}{c}\text { WRQ5 vs } \\
\text { ORFR } \\
\text { Q4+Q5 }\end{array}$ & \\
\hline Energy (kJ/d) & 87 & 86 & $0.62^{\text {*** }}$ \\
\hline Protein (g) & 67 & 57 & $0.33^{*}$ \\
\hline Total fat $(\mathrm{g})$ & 93 & 64 & 0.54 \\
\hline Saturated fat (g) & 93 & 79 & $0.64 * *$ \\
\hline Monounsaturated fat $(\mathrm{g})$ & 80 & 71 & $0.47^{* *}$ \\
\hline Polyunsaturated fat (g) & 80 & 71 & $0.34 *$ \\
\hline Cholesterol (mg) & 80 & 79 & $0.5 I^{* *}$ \\
\hline Total carbohydrates (g) & 87 & 86 & $0.63^{* *}$ \\
\hline Dietary fibre $(\mathrm{g})$ & 80 & 79 & $0.5 I^{* *}$ \\
\hline Alcohol (g) & 73 & 93 & $0.64 * *$ \\
\hline Protein (E\%) & 60 & 64 & $0.48^{* *}$ \\
\hline Total fat (E\%) & 60 & 71 & $0.42^{* *}$ \\
\hline Saturated fat (E\%) & 60 & 79 & $0.58^{* *}$ \\
\hline Monounsaturated fat (E\%) & 67 & 77 & $0.33^{*}$ \\
\hline Polyunsaturated fat (E\%) & 60 & 71 & $0.37 * *$ \\
\hline Alcohol (E\%) & 78 & 93 & $0.65 * *$ \\
\hline
\end{tabular}

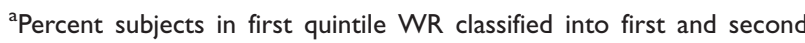
quintiles in ORFR.

bercent subjects in fifth quintile WR classified into fourth and fifth quintiles in ORFR.

'Significance of the Spearman correlation: ${ }^{*} p<0.01$; ${ }^{*} p<0.001$.

estimate nutrient and food intake in different groups (5, $15,26)$. The record book has proven to be very useful in larger dietary investigations, but has also been found to have some limitations $(5,15)$. One important advantage of a pre-coded record book, compared with open-ended records, is that considerable time may be saved by not having to code and enter data. Becker et al. (15) suggested that the time reduction was almost $50 \%$ : coding and data entry from the pre-coded record took $1.3 \mathrm{~h}$ per person as compared to $2.5 \mathrm{~h}$ per person for the WR. In a study including 500 participants, this means a saving of four man-months of work $(15,27)$. In the present study, a precoded record book designed for optical scanning was used, which also considerably reduced the time-consuming step of entering the data manually (15).

As reported by others, and shown here, underestimation of food intake seems to be a 'general problem', as shown by various assessment methods $(1,2,4,5,14$, $15,23,28,29)$. The reported EIs obtained here are comparable with those from a number of other large investigations in which seven-day food records were
Table 4. Cross-classification (quintiles) and Spearman correlation for daily intakes of selected nutrients measured by the ORFR and the weighed record (WR) $(n=73)$

\begin{tabular}{|c|c|c|c|}
\hline \multirow[t]{2}{*}{ Nutrients } & \multicolumn{2}{|c|}{$\begin{array}{c}\text { Cross-classification, \% } \\
\text { in quintiles }\end{array}$} & \multirow{2}{*}{$\begin{array}{c}\begin{array}{c}\text { Spearman } \\
\text { correlation }\end{array} \\
r\end{array}$} \\
\hline & $\begin{array}{l}\text { WR QI } \\
\text { vs ORFR } \\
\mathrm{QI}^{+} 2^{\mathrm{a}}\end{array}$ & $\begin{array}{l}\text { WR Q5 } \\
\text { vs ORFR } \\
\text { Q4+Q5 }\end{array}$ & \\
\hline Vitamin A (retinol eqv.) & 63 & 57 & $0.13^{*}$ \\
\hline Retinol (mg) & 60 & 64 & $0.34 *$ \\
\hline$\beta$-carotene (mg) & 40 & 64 & $0.29 *$ \\
\hline Vitamin D $(\mu \mathrm{g})$ & 67 & 43 & $0.08 *$ \\
\hline$\alpha$-tocopherol (mg) & 73 & 57 & $0.36^{*}$ \\
\hline Vitamin C (mg) & 73 & 79 & $0.42 * *$ \\
\hline Thiamin (mg) & 67 & 57 & $0.29 *$ \\
\hline Riboflavin (mg) & 80 & 43 & $0.38 *$ \\
\hline Niacin (mg) & 53 & 40 & $0.20 *$ \\
\hline Niacin eqv. (mg) & 73 & 57 & $0.33^{*}$ \\
\hline Calcium (mg) & 73 & 71 & $0.47^{* *}$ \\
\hline Phosphorus (g) & 80 & 86 & $0.68 * *$ \\
\hline Magnesium (mg) & 73 & 50 & $0.4 I^{* *}$ \\
\hline Sodium (mg) & 60 & 64 & $0.38 * *$ \\
\hline Potassium (mg) & 53 & 64 & $0.30 *$ \\
\hline Iron (mg) & 73 & 71 & $0.42 * *$ \\
\hline Zinc (mg) & 60 & 64 & $0.37 * *$ \\
\hline Selenium $(\mu \mathrm{g})$ & 73 & 64 & $0.33 * *$ \\
\hline
\end{tabular}

${ }^{\text {aPercent }}$ subjects in first quintile WR classified into first and second quintiles in ORFR.

${ }^{b}$ Percent subjects in fifth quintile WR classified into fourth and fifth quintiles in ORFR.

Significance of the Spearman correlation: ${ }^{*} p<0.0$ I; ${ }^{*} p<0.00$ I.

also employed $(5,15,28)$. In the present study, the proportions of energy-providing nutrients did not differ significantly between the two methods, indicating that under-reporting of this aspect was not specific to the method used (Table 3).

However, significantly lower EIs were obtained when using ORFR than when using WR. There may be several reasons for this under-reporting. One plausible reason may be that ORFR includes 'standard' recipes. This means that the fat used for cooking, i.e. included in the recipes, is of the same quality/type (amounts of total fat and fatty acid composition). Thus, if the subject uses other cooking fats with a different fat content or with a different fatty acid composition, this will not be recorded or calculated. The true picture of the dietary fat intake is thus limited when using ORFR. This may explain the significant differences found for some of the individual fatty acids. The same observations have been made earlier $(4,5,15,17)$. However, when using WR, the subjects are more likely to specify the type of cooking fat, as well as the true amounts 
Table 5. Intake of protein (g/d) measured by ORFR, WR and 24-h urine nitrogen excretion (UN). The figures are presented as mean and (SD) and their correlation $(n=59)$

\begin{tabular}{lllll}
\hline Methods & Mean & SD & $\begin{array}{c}\text { Difference } \\
\text { from UN (\%) }\end{array}$ & $\begin{array}{c}\text { Spearman } \\
\text { correlation }\end{array}$ \\
\hline ORFR (g/d) & $68.5^{*}$ & $(19.3)$ & -31.4 & $0.59^{*}$ \\
WR $(g / d)$ & $77.5^{*}$ & $(15.5)$ & -22.4 & $0.27^{* *}$ \\
UN & 99.9 & $(22.9)$ & & \\
\hline
\end{tabular}

Significance difference from urine protein: ${ }^{*} p<0.0001$.

Significance of Spearman correlation: ${ }^{* *} p<0.05$.

of spreads they consume, because they actually weigh every single food item and the amount they eat.

In the present investigation, calculations of the adequacy of the reported EI values were made on the basis of estimated BMR values as suggested by FAO/WHO/UNU $(21,22)$ and the cut-off points suggested by Goldberg et al. (23). Based on these calculations, a large proportion of the subjects were categorised as under-reporters using both methods, though a larger number using the ORFR method. The proportion of subjects with implausibly low reported EIs corresponds well with the findings of other surveys in which a record book (pre-printed, but not optically readable) was used $(5,15,26)$. There is some uncertainty in the calculations of under-reporting because physical activity, specific to this study, was not assessed and cut-off limits for the EI:BMR ratio were based on those calculated by Goldberg et al., with a sedentary Physical Activity Level of 1.55 for $n=1(4,23)$.

It was further found that both assessment methods yielded lower estimates for protein intake compared to estimates based on UN excretion (Table 5). The lowest calculated intakes were obtained by the ORFR. Despite that only a single 24-h urine was collected, correlation coefficient (Spearman) for ORFR was relatively high (0.59), and close to figures reported by Bingham et al. (13) for estimated food records $(0.60-0.70)$ using eight 24 h urine per subject. Further, when we checked our results using PABA, we did not include those who had $<85 \%$ completeness, as such results obviously indicate significant underestimation. Similar results have been reported by Becker et al. (15), also based on comparison of an open WR with the pre-coded record book. Some of the portion sizes used in the ORFR provide the most probable explanation for the low figures obtained (5, $15,30)$. An analysis of the food consumption figures is very much in line with the lower energy findings, as well as with some lower nutrient intake figures, when using the ORFR. Lower consumption of, e.g. meat, milk and fat products can be associated with lower intakes of energy, as well as with lower intakes of the major energy-yielding nutrients such as total fat and protein, and perhaps also with some of the vitamins and minerals. Further, lower consumption of bread and cereal products, as well as vegetables, may explain lower figures for carbohydrates and dietary fibre.

Table 6. Average consumed amounts, mean and (SD) of food among healthy, elderly men according to the optically readable food record (ORFR) and the weighed record (WR) $(n=73)$

\begin{tabular}{|c|c|c|c|c|c|}
\hline \multirow{2}{*}{$\begin{array}{l}\text { Food group } \\
\text { Spreads }\end{array}$} & \multicolumn{2}{|c|}{ ORFR } & \multicolumn{2}{|c|}{ WR } & \multirow{2}{*}{$\frac{p \text {-Value }}{0.69}$} \\
\hline & 30 & (19) & 31 & $(15)$ & \\
\hline Cheese & 32 & $(22)$ & 27 & $(19)$ & 0.02 \\
\hline Milk & 314 & $(163)$ & 270 & (139) & $<0.01$ \\
\hline Potatoes & 154 & $(70)$ & 158 & $(65)$ & 0.62 \\
\hline Vegetables & 79 & (55) & 105 & (65) & $<0.01$ \\
\hline Fruit and berries & 114 & (85) & 116 & (95) & 0.91 \\
\hline Juice & 18 & (39) & 22 & (55) & 0.48 \\
\hline Bread, cereals and pasta & 231 & (95) & 258 & $(1 \mid 2)$ & 0.01 \\
\hline Cakes and biscuits & 62 & (55) & 71 & $(48)$ & 0.02 \\
\hline Meat and meat products & 103 & (43) & 120 & (47) & 0.01 \\
\hline Fish & 31 & (22) & 53 & (35) & $<0.001$ \\
\hline Egg & 17 & (20) & 17 & (17) & 0.61 \\
\hline Ice cream & 5 & (5) & 6 & (10) & 0.42 \\
\hline Jam, sweet drinks and desserts & 64 & (93) & 89 & (89) & 0.04 \\
\hline Chocolate, sweets and sugar & 8 & $(12)$ & 12 & $(14)$ & $<0.01$ \\
\hline Coffee & 492 & (206) & 348 & $(169)$ & $<0.001$ \\
\hline Tea & 135 & $(165)$ & 113 & $(145)$ & 0.03 \\
\hline Alcoholic beverages & 178 & $(168)$ & 136 & $(12)$ & $<0.001$ \\
\hline
\end{tabular}


In general, the portion sizes used in our ORFR may have been too small for various food items and dishes. 'Flat slope syndrome' is another explanation, suggested by Gibson (31), for the tendency to overestimate low intakes and underestimate high intakes, and this explanation may also apply to the subjects in the present investigation. In an evaluation of portion sizes, Håglin and co-workers (30) showed that choosing incorrect pictures may result in both under- and over-estimations.

Although most elderly people are thought to have a regular meal pattern and eat most of their food at home, they may forget to weigh everything. This could explain the low protein intakes estimated when using the WR. As stated by Bingham (12), energy and protein intakes have been found to be under-estimated by as much as $20 \%$ according to various dietary surveys $(12,33)$. Our results, as well as those of others (32), suggest that improvement of methods for estimating portion sizes should be a priority in future dietary assessment methodology.

After the present study was performed, the ORFR was also investigated by Rosell et al. (34). The aim of their study was to investigate how much of the energy and nutrients contributed by foods that has to be reported in free text. The authors concluded that to reduce the level of under-reporting, emphasis should be placed on improving the recording of between-meal eating. However, we would like to emphasise the two important advantages of a pre-coded, ORFR: the recorder and the experimenter save a considerable amount of time and the accuracy of coding and data entry is increased. In a pilot study comprising 35 subjects, time savings in data entering, data checks and nutrient analysis were on average $30 \mathrm{~min}$ for the ORFR compared with the manual pre-printed record book (Carlsson \& Johansson, unpublished data). Therefore, after the suggested adjustments especially in, portion sizes, the ORFR could be seen as a useful tool in a variety of food and nutrition studies.

\section{Conclusions}

The above findings indicate that when a pre-coded food record is used this is designed for scanning, the following advantages ensue:

1) It is less time-consuming for subjects to record their food intake because there is no need for weighing and writing.

2) It allows more efficient data processing, e.g. by limiting time spent on data entry.

3) A pre-coded and ORFR is less expensive to process than a manual version is.

4) Emphasis should be put on estimations of the type and amount of fat used in order to obtain a valid assessment of total fat and fat quality.
5) The portion sizes should be estimated carefully measured to reflect the actual portion sizes in the study population.

\section{Conflict of interest and funding}

The author has not received any funding or benefits from industry to conduct this study.

\section{References}

1. Lissner L, Habicht J-P, Stropp BJ, Levitsky DA, Haas JD, Roe DA. Body composition and energy intake: do overweight women overeat or underreport? Am J Clin Nutr 1989; 49: $320-5$.

2. Bandini LG, Schoeller DA, Cyr HN, Dietz WH. Validity of reported energy intake in obese and non-obese adolescents. Am J Clin Nutr 1990; 52: 421-5.

3. Schoeller DA. How accurate is self-reported dietary energy intake? Nutr Rev 1990; 48: 373-8.

4. Martin GS, Tapsell LC, Denmeade S, Batterham MJ. Relative validity of a diet history interview in an intervention trial manipulating dietary fat in the management of Type II diabetes mellitus. Prev Med 2003; 36: 420-8.

5. Nydahl M, Gustafsson I-B, Mohsen R, Vessby B. The food and nutrient intake of Swedish non-smokers and smokers. Scand $\mathbf{J}$ Nutr 1996; 40: 64-9.

6. Macdiarmid JI, Blundell JE. Dietary under-reporting: what people say about recording their food intake. Eur J Clin Nutr 1997; 51: 199-200.

7. Goldberg GR, Black AE. Assessment of the validity of reported energy intakes - review and recent developments. Scand J Nutr 1993; 42: 6-9.

8. Willett WC, Howe GR, Kushi LH. Adjustment for total energy intake in epidemiologic studies. Am J Clin Nutr 1997; 65 (Suppl 4): 1220S-8S.

9. Isaksson B. Urinary nitrogen output as a validity test in dietary surveys. Letters to the editor. Am J Clin Nutr 1980; 46: 729-34.

10. Bingham SH, Cummings JH. Urine nitrogen as an independent validatory measure of dietary intake: a study of nitrogen balance in individuals consuming their normal diet. Am J Clin Nutr 1985; 42: 1276-89.

11. Bingham SA, Williams R, Cole TJ, Price CP, Cummings JH. Reference values for analyses of 24-h urine collections known to be complete. Ann Clin Biochem 1988; 25: 610-9.

12. Bingham SA. The use of 24-h urine samples and energy expenditure to validate dietary assessments. Am J Clin Nutr 1994; 59 (Suppl 1): 227S-31S.

13. Bingham SA, Cassidy A. Validity of weighed records and other methods of dietary assessment using the 24-h urine nitrogen technique and other biological markers. Br J Nutr 1995; 73: 531-50.

14. Haraldsd'ottir J. Minimizing error in the field: quality control in dietary surveys. Eur J Clin Nutr 1993; 47(Suppl S2): S19-24.

15. Becker W, Lennernäs M, Gustafsson I-B, Haraldsd'ottir J, Nydahl M, Vessby B, et al. Precoded food records compared with weighed food records for measuring dietary habits in a population of Swedish adults. Scand J Nutr 1998; 42: 145-9.

16. Becker W. Befolkningens kostvanor och näringsintag i Sverige 1989. Metod- och resultatanalys. Food habits and nutrient intake in Sweden 1989 (In Swedish with English summary). Sweden: National Food Administration; 1994.

17. Hedstrand H. A study of middle-aged men with a particular reference to risk factors for cardiovascular disease. Ups J Med Sci 1975; (Suppl 19): 1-61. 
18. PC-Kost-94. (1994): National Food Database, Sweden. Statens Livsmedelsverk/National Food Administration, Sweden.

19. Nordin M. MA Ts. Nutrient calculation system designed for research and education. Västerås: Rudans Lättdata; 1994.

20. SLV Database. The National Food Administration, Sweden: SLV Data base. Nordin M MATS-program, 1990.

21. Schofield WN, Schofield C, James WPT. Basal metabolic rate. Hum Nutr Clin Nutr 1985; 39C (Suppl 1): 1-6.

22. FAO/WHO/UNU. Report of a joint expert consultation. Energy and protein requirements. WHO Technical Report Series No 724. Geneva: WHO; 1985.

23. Goldberg GR, Black AE, Jebb SA, Cole TJ, Murgatroyd PR, Coward WA, et al. Critical evaluation of energy intake data using fundamental principles of energy physiology: 1. Derivation of cut-off limits to identify underreporting. Eur J Clin Nutr 1991; 45: 569-81.

24. SAS Institute Inc. SAS user's guide. Cary, NC: SAS; 1982.

25. Siegel S. Non-parametric statistics for behavioral sciences. Series in psychology. New york. McGraw Hill; 1956, p. 202.

26. Becker W, Foley S, Shelley E, Gibney M. Energy underreporting in Swedish and Irish dietary surveys: implications for food-based dietary guidelines. Br J Nutr 1999; 81(Suppl 2): S127-31.

27. Haraldsdóttir J. Dietary composition among subjects reporting implausibly low energy intake (EI/BMRest). Am J Clin Nutr 1997; 65: 4S, 1360S.

28. Jorgensen LM, Isaksson B, Schroll M. Reproducibility and validity of 7-day food records. Eur J Clin Nutr 1992; 46: 729-34.
29. Bingham SA. Validation of dietary assessment through biomarkers. In: Kok FJ, Vant Veer P, eds. Biomarkers of dietary exposure. London: Smith-Gordon; 1991, pp. 41-52.

30. Håglin L, Hagman U, Nilsson M. Evaluation of the Meal Model "Matmallen". A means of estimating consumed amounts of food. Scand J Nutr 1995; 39: 79-83.

31. Gibson SR. Sources of error and variability in dietary assessment methods: a review. J Can Diet Assoc 1987; 48: 150-5.

32. Buzzard IM, Sievert YA. Research priorities and recommendations for dietary assessment methodology. Am J Clin Nutr 1994; 59 (Suppl 1): 275S-80S.

33. Livingstone MBE, Prentice AM, Coward WA, Strain JJ, Black AE, Davies PSW, et al. Validation of estimates of energy intake by weighed dietary records and diet history in children and adolescents. Am J Clin Nutr 1992; 56: 29-35.

34. Rosell M, Hellénius M-L, de Faire U, Berglund L, Gustafsson IB, Johansson G. Contribution of a manually part in an optically readable, precoded seven-day food record for the intake of energy, nutrients and foods. Scand J Nutr 2003; 47: 123-31.

\section{*Margaretha Nydahl}

Department of Food, Nutrition and Dietetics

Uppsala University, BMC, Husargatan 3

SE-752 37 Uppsala, Sweden

Email: margaretha.nydah|@ikv.uu.se 